\title{
A educação do campo e a interdisciplinaridade: desafios e possibilidades
}

\author{
The rural education and interdisciplinarity: challenges and opportunities
}

\section{Luiz Felipe Ribeiro', Berenice Bueno ${ }^{2}$}

\begin{abstract}
${ }_{1}^{1}$ Bacharel em Gestão Ambiental pela UNIPAMPA, Campus de São Gabriel/RS. Pós-graduado em Educação: Interdisciplinaridade e Transversalidade pela Universidade Federal do Pampa - UNIPAMPA. ${ }^{2}$ Licenciada em Ciências Biológicas, Especialista em Educação: Interdisciplinaridade e Transversalidade pela Universidade Federal do Pampa - UNIPAMPA. Docente no curso de Ciências Biológicas da UNIPAMPA, Campus de São Gabriel/RS.
\end{abstract}

\begin{abstract}
Resumo
O presente artigo trata das dificuldades encontradas por educadores da Educação Básica da Escola Estadual de Ensino Fundamental Ataliba Rodrigues das Chagas, de São Gabriel/RS, para aplicar a interdisciplinaridade em sala de aula, bem como tal fato tem se tornado cada vez mais um desafio à carreira docente. Trata-se de uma pesquisa básica de cunho explicativo que envolveu a aplicação de questionários para os docentes do Ensino Fundamental II e contou com uma atividade interventiva cujos objetivos eram identificar o nível de conhecimento do corpo docente, sobre a Interdisciplinaridade; proporcionar fundamentação teórica e auxiliar na elaboração um projeto didático interdisciplinar que atendesse as necessidades específicas dos discentes da escola do campo. Os resultados obtidos mostraram que o currículo desenvolvido segue os princípios das escolas urbanas, não se adequando às peculiaridades da escola do campo. Quanto à interdisciplinaridade, o corpo docente necessita de mais formação teórica quanto ao assunto estando todos dispostos a re (significar) sua prática em busca de uma pedagogia interdisciplinar.
\end{abstract}

Palavras-chave: Escola do Campo. Interdisciplinaridade. Projeto

\begin{abstract}
This article deals with the difficulties encountered by teachers of basic education State Elementary School Ataliba Rodrigues das Chagas, of St Gabriel / RS to apply interdisciplinarity in the classroom, and this fact has become increasingly challenging to career teaching. It is an explanatory nature applied research that involved the use of questionnaires for teachers of elementary school II and had an interventional activity whose objectives were to identify the body of knowledge level about these Interdisciplinary; provide theoretical basis and help to develop an interdisciplinary educational project that would meet the specific needs of the field school students. The results showed that this school developed the curriculum follows the principles of urban schools, not adapting to the peculiarities of the field school. As for interdisciplinary, the faculty needs more theoretical training on the subject being all motivated and willing to re (mean) its practice in search of an interdisciplinary pedagogy.
\end{abstract}

Keywords: Field School. Interdisciplinary. Project 


\section{INTRODUÇÃO}

A Educação do Campo originou-se no processo de luta dos movimentos sociais camponeses e por isso, traz de forma clara sua intencionalidade maior: a construção de uma sociedade sem desigualdades e com justiça social. Ela se configura como uma reação organizada dos camponeses ao processo de desapropriação de suas terras e de seu trabalho pelo avanço do modelo agrícola hegemônico na sociedade brasileira, estruturado a partir do agronegócio. A luta dos trabalhadores para garantir o direito à escolarização e ao conhecimento faz parte das suas estratégias de resistência, construídas na perspectiva de manter seus territórios de vida, trabalho e identidade, e surgiu como reação ao histórico conjunto de ações educacionais que, sob a denominação de Educação Rural, não só mantiveram o quadro precário de escolarização no campo, como também contribuíram para perpetuar as desigualdades sociais naquele território.

Ao entrar na década de 1960, a educação começou em processo de universalização para atender as novas necessidades da economia em curso. As escolas, agora públicas, também destinadas aos pobres, à classe trabalhadora, passaram a ter como finalidade, a formação de técnicos para a indústria. A partir desta década muitas escolas situadas nas áreas rurais começaram a ser desativadas, ficando seus prédios abandonados. Na prática, a escola no Brasil historicamente produziu um quadro de exclusão das camadas baixas da sociedade.

Com a aprovação da Lei de Diretrizes e Bases da Educação Nacional (LDB), no 9394/96 e com a publicação dos Parâmetros Curriculares Nacionais (PCN's), ocorrido em 1997, e que traziam consigo a proposta da transversalidade de diferentes temas dentro das diversas áreas do conhecimento. Surgia aí uma oportunidade para a implantação da interdisciplinaridade.

Desta forma, o presente trabalho propôs-se a identificar como ocorre a relação entre os docentes da Escola Estadual de Ensino Fundamental Ataliba Rodrigues das Chagas, de São Gabriel/RS, e o tema interdisciplinaridade, visando propor a elaboração de um projeto capaz de contemplar um tema pertinente, voltado à educação do campo que possa ser abordado em uma metodologia que contemple a contribuição de diferentes perspectivas disciplinares.

A interdisciplinaridade surge como uma das respostas à necessidade de uma reconciliação epistemológica do conhecimento devido à fragmentação do saber ocorrido com a revolução industrial e a necessidade de mão de obra especializada. Atualmente, busca-se conciliar os conceitos pertencentes às diversas áreas do conhecimento a fim de promover avanços na produção de novos conhecimentos ou mesmo novas formas de desenvolvimento do raciocinio e questionanento.

A prática interdisciplinar já está bem difundida atualmente. Porém, poucos educadores estão habilitados a trabalhar utilizando esta metodologia, porque são oriundos de um ensino fragmentado, dividido em áreas do conhecimento. No entanto, acredita-se que devido às peculiaridades da Escola do Campo possam existir caminhos que favoreçam tal ação metodológica visto que, os professores realizam viagens, tendo a possibilidade de dialogarem e/ou, esporadicamente, planejarem ações em conjunto. $\mathrm{O}$ fato da Escola do Campo ter características peculiares podem apontar temas específicos da sua realidade que se adéquem a uma ação mais interdisciplinar.

\section{INTERDISCIPLINARIDADE: A ARTICULAÇÃO DO TODO COM AS PARTES}

Para o desenvolvimento deste trabalho, realizou-se uma pesquisa bibliográfica de diversos autores que abordam o tema.

A origem da fragmentação do conhecimento é citada freqüentemente na literatura como sendo cartesiana. Embora não haja consenso sobre essa origem, Descartes propõe no livro Discurso do Método, em 1637, que para se resolver uma questão complexa deve-se decompô-la em partes menores a fim de simplificar o problema. A união da resolução das partes daria a resolução do todo. 
Segundo Petraglia (1993), o movimento da interdisciplinaridade surgiu na Europa, essencialmente, na França e na Itália, em meados da década de 60. Nesta época, os movimentos estudantis lutavam por um novo estatuto de universidade e escola. Também, por parte de alguns professores, apareceram várias tentativas de buscar o rompimento com uma educação segmentada.

Hilton Japiassu e Ivani Fazenda, ao final da década de 60, foram os primeiros teóricos brasileiros a produzir uma extensa obra no campo pedagógico. São estes dois teóricos que influenciam praticamente toda a produção bibliográfica sobre o assunto no Brasil.

Para Japiassu (1976), a interdisciplinaridade surge como uma necessidade imposta pelos teóricos brasileiros a descrever sobre a temática interdisciplinar, sendo que este veio a trabalhar o conceito que denominamos campo epistemológico. Assim, é necessário que haja pontes de ligação entre as disciplinas, já que elas se mostram muitas vezes dependentes umas das outras, tendo em alguns casos o mesmo objeto de estudo, variando somente em sua análise.

De acordo com Fazenda (1999), um ensino interdisciplinar requer um trabalho conjunto entre alunos e professores assim como de gestores e demais sujeitos integrantes da comunidade escolar, ou seja, a integração não deve ocorrer apenas entre as disciplinas escolares, mas também entre pessoas, conceitos, informações e metodologias aplicadas no ensino.

A interdisciplinaridade vai além da simples junção de conteúdos específicos de cada disciplina. É preciso que os professores planejem as aulas juntos e que possam se apropriar de conceitos de outras áreas, enriquecendo o conhecimento. Percebe-se que o termo adquiriu uma conotação de modismo, mas na prática nem sempre acontece a interdisciplinaridade. Tem educadores que dizem fazer, mas não o fazem; enquanto outros, sem saber, atuam interdisciplinarmente. Frequentemente os professores não recebem capacitação suficiente para compreender determinada metodologia de ensino, mas são cobrados a aplicá-la, cometendo algumas distorções.

Conforme aborda Jantsch (1995), a interdisciplinaridade é marcada pelo intenso diálogo entre os diversos campos do conhecimento e há diferentes níveis, com características próprias.

O primeiro é a Multidisciplinaridade que ocorre quando o mesmo assunto é trabalhado em diversas disciplinas, mas não há uma ligação entre uma e outra. As ações pedagógicas são simultâneas, mas não interligadas.

O segundo nível é a Pluridisciplinaridade que ocorre quando as disciplinas afins se aproximam para construir o conhecimento juntas, como na preparação dos estudantes para o Exame Nacional do Ensino Médio (ENEM).

No terceiro nível surge a Interdisciplinaridade onde as ações são coletivas, estão interligadas por uma problemática, existe um coordenador que organiza e estabelece a ligação entre as disciplinas para garantir a caminhada na resolução da problemática em questão.

E, no quarto e último nível, encontra-se a Transdisciplinaridade onde, definitivamente, não há barreiras disciplinares. A ligação pode ser feita por meio de temas transversais que abrangem as disciplinas.

É quanto ao educador Fazenda (1994) constrói um perfil de um professor portador de uma atitude interdisciplinar, que se caracterizaria por ter gosto pelo conhecer e pesquisar, ter um comprometimento diferenciado para com os alunos, usar novas técnicas e procedimentos de ensino. Também de acordo com Fazenda (1992) "não se ensina, nem se aprende, apenas vive-se, exerce-se todo o indivíduo engajado nesse processo será não o aprendiz, mas, na medida em que familiarizar-se com as técnicas e quesitos básicos o criador de novas estruturas, novos conteúdos, novos métodos, será o motor de transformação".

Citando novamente Fazenda (1999) a indefinição sobre interdisciplinaridade origina-se ainda dos equívocos sobre o conceito de disciplina. A polêmica sobre disciplina e interdisciplinaridade possibilita uma abordagem pragmática em que a ação passa a ser o ponto de convergência entre o fazer e o pensar interdisciplinar.

É preciso estabelecer uma relação de interação entre as disciplinas, que seria a marca fundamental das relações interdisciplinares. Conforme Morin (2000), o ensino por disciplina, fragmentado e dividido, 
impede a capacidade natural que o espírito tem de contextualizar, e essa capacidade que deve ser estimulada e deve ser desenvolvida pelo ensino de ligar as partes ao todo e o todo às partes.

Já para Ferreiro (1996), o conhecimento é fruto da construção pessoal e ativa do aluno e o professor é um agente mediador que precisa criar situações desafiadoras em contexto significativo ao aluno, permitindo que ele explore várias possibilidades, mesmo que sejam contraditórias ou falsas. As contradições que fazem parte do processo de aprendizagem são depois esclarecidas, exploradas e discutidas.

Um ensino pautado na prática interdisciplinar pretende formar alunos com uma visão global de mundo, aptos para "articular, religar, contextualizar, situar-se num contexto e, se possível, globalizar, reunir os conhecimentos adquiridos" (MORIN, 2002, p. 29). A visão de mundo, pautada na relação entre o todo e as partes dão o respaldo necessário ao conceito de interdisciplinaridade que concebemos. Este conceito está apoiado na complexidade, no objetivo de alcançar uma visão global de mundo, na abordagem de um tema ou tópico que esteja acima das barreiras disciplinares, isto é, na tentativa de abordar o tema como um todo (em sua relação com as partes) e com as disciplinas que o compõe.

Para Perrenoud (1997) aponta uma natureza de obstáculos, visto que a interdisciplinaridade exige a modificação dos hábitos dos alunos, que necessitarão maior envolvimento nas tarefas, assim como mais transparência na elaboração de seus trabalhos e estudos. O mesmo diz respeito aos profissionais. Para que seja possível estabelecer um trabalho interdisciplinar, é preciso que as ações de cada educador sejam transparentes, que se saiba o que se faz e que se disponibilize a pensar junto com os demais profissionais envolvidos no projeto, considerando as necessidades que a questão impõe.

Todas essas modificações exigem alterações nos hábitos, pois o saber não é apenas uma disciplina, ele incorpora-se às relações interpessoais e a própria corporeidade do sujeito.

No modelo disciplinar, a produção do conhecimento é individual. No modelo interdisciplinar fazse necessária à inter-relação pessoal. No modelo disciplinar não há iniciativa de educadores e educandos; no modelo interdisciplinar, há iniciativa dos educadores e educandos, assim como a autonomia do grupo é promovida.

A Lei de Diretrizes e Bases da Educação Nacional (LDB), lei no 9394/96, trouxe em si avanços e proporcionou conquistas voltadas às políticas educacionais para o campo, mesmo que nas entrelinhas da LDB estejam os interesses neoliberais. Por outro lado, o artigo 28 da LDB aponta direcionamento específico à escola do campo.

O Artigo 28 nos indica que:

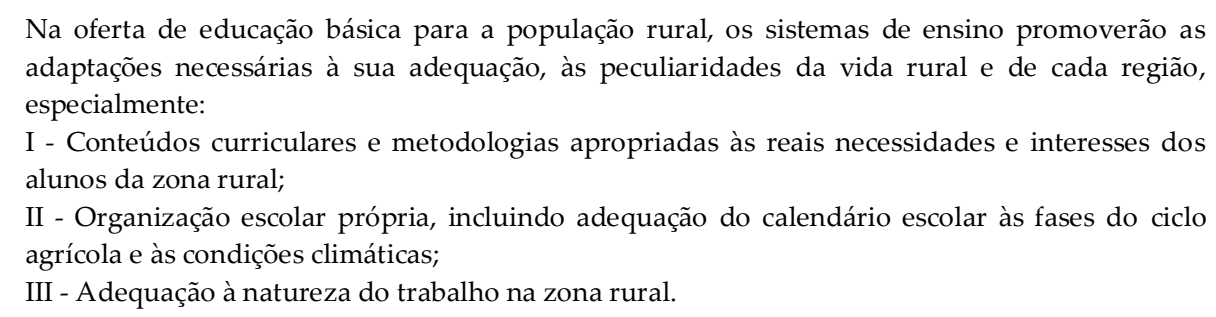

No que diz respeito à legislação, o Movimento da Educação do Campo acumulou, a partir de suas diversas lutas (nacionais, estaduais e municipais), um conjunto importante de instrumentos legais que reconhecem e legitimam as condições necessárias para que a universalidade do direito à educação se exerça, respeitando as especificidades dos sujeitos do campo. Neste sentido, a interdisciplinaridade seria uma proposta capaz de alavancar tais especificidades e colocá-las em discussão tornando o saber mais concreto e significativo.

Para isso, a interdisciplinaridade deve ser buscada, exercida no cotidiano escolar e ter um fim prático, produzir resultados substanciais na sociedade. 
Quando se discute a questão do conhecimento pedagógico, ocorre forte tendência em se colocar o problema de um ponto de vista puramente epistemológico, com desdobramento no curricular. Mas entendo que é preciso colocá-lo sob o ponto de vista da prática efetiva, concreta, histórica. [...] a função do conhecimento é substantivamente intencionalizar a prática; ele é a única ferramenta de que dispomos para tanto.

O conhecimento aparece, aqui, como alicerce para as práticas sociais, como instrumento de luta de classes, de inserção social, de consciência crítica, de cidadania. Severino $(2007$, p. 36) afirma que:

\footnotetext{
O saber aparece, portanto, como instrumento para o fazer técnico-produtivo, como mediação do poder e como ferramenta da própria criação dos símbolos, voltando-se sobre si mesmo, ou seja, é sempre um processo de intencionalização. Assim, é graças a essa intencionalização que nossa atividade técnica deixa de ser mecânica e passa a se dar em razão de uma projetividade, o trabalho ganhando sentido. Do mesmo modo, a atividade propriamente política se ideologiza, e a atividade cultural transfigura a utilidade pragmática imediata de todas as coisas.
}

Dentro desse contexto, o planejamento, na prática educacional, torna-se fundamental na contextualização do fazer pedagógico interdisciplinar.

Os Parâmetros Curriculares Nacionais do Ensino Médio (PCNs) (1997), também orientam para o desenvolvimento de um currículo que contemple a interdisciplinaridade como algo que vá além da justaposição de disciplinas e, ao mesmo tempo, evite a diluição das mesmas de modo a se perder em generalidades.

O trabalho interdisciplinar precisa "partir da necessidade sentida pelas escolas, professores e alunos de explicar, compreender, intervir, mudar, prever, algo que desafia uma disciplina isolada e atrai a atenção de mais de um olhar, talvez vários" (BRASIL, 2002, p. 88).

Na perspectiva escolar, a interdisciplinaridade não tem a pretensão de criar novas disciplinas ou saberes, mas de utilizar os conhecimentos de várias disciplinas para resolver um problema ou compreender um determinado fenômeno sob diferentes pontos de vista. "A interdisciplinaridade tem uma função instrumental. Trata-se de recorrer a um saber diretamente útil e utilizável para resolver as questões e aos problemas sociais contemporâneos (Parâmetros Curriculares Nacionais - Ensino Médio. Brasília: MEC, 2002, p. 34)".

Portanto, a interdisciplinaridade na escola do campo vem complementar as disciplinas, criando no conceito de conhecimento uma visão de totalidade, onde os alunos possam perceber que o mundo onde estão inseridos é composto de vários fatores, que a soma de todos, juntamente com suas práticas e vivências, formam uma complexidade.

\section{METODOLOGIA}

A pesquisa realizada classifica-se como básica e de cunho explicativo que, segundo Gil (1999), mais aprofunda o conhecimento da realidade, pois tenta explicar a razão e as relações de causa e efeito dos fenômenos. O procedimento de coleta de dados deu-se em dois momentos. Primeiramente, foi aplicado um questionário aos professores do Ensino Fundamental II, composto por seis perguntas fechadas e três perguntas abertas sobre o tema Interdisciplinaridade.

Em um segundo momento houve uma intervenção pedagógica com os referidos professores, que pode ser definida como uma pesquisa que envolve o planejamento e a implementação de interferências (mudanças, inovações pedagógicas) - destinadas a produzir avanços, melhorias, nos processos de aprendizagem dos sujeitos que delas participam e a posterior avaliação dos efeitos dessas interferências.

Outro ponto relevante e que fez parte do desenvolvimento deste estudo foi a pesquisa bibliográfica. A importância da pesquisa bibliográfica em trabalhos científicos pode ser confirmada, por meio do texto que segue: “Qualquer espécie de pesquisa, em qualquer área, supõe e exige pesquisa bibliográfica 
prévia, quer à maneira de atividade exploratória, quer para o estabelecimento do status quaestionis, quer para justificar os objetivos e contribuições da própria pesquisa" (RUIZ, 1992, p. 57).

\section{DESCRIÇÃO DOS DADOS COLETADOS}

Neste texto do artigo estão descritos os dados desta pesquisa, os quais foram obtidos por meio da aplicação de um questionário para educadores da Escola Estadual de Ensino Fundamental Ataliba Rodrigues das Chagas, seguida da realização de uma atividade interventiva que ocorreu no dia 21 de julho de 2015, na sala de reuniões da Universidade Federal do Pampa, conforme figura 4.

Estavam presentes na atividade interventiva nove professores que atuam no Ensino Fundamental II. Destes, seis relataram atuar na sua área de formação e três indicaram que atuam em outra área.

Todos indicaram que trabalham 40 horas semanais e quando questionados quanto ao ano da graduação, cinco educadores indicaram ter concluído esta etapa entre os anos 2000 e 2010. Apenas quatro educadores são formados nas décadas de 80 e 90.

Quanto à realização de projetos, na sua maioria, os educadores responderam que possuem essa prática envolvendo a disciplina que atuam e o contexto da Escola ou em um contexto de agrupamento, conforme mostra o gráfico 1 .

Gráfico 1- Como são desenvolvidos os projetos no âmbito da escola pelos professores do Ensino Fundamental.

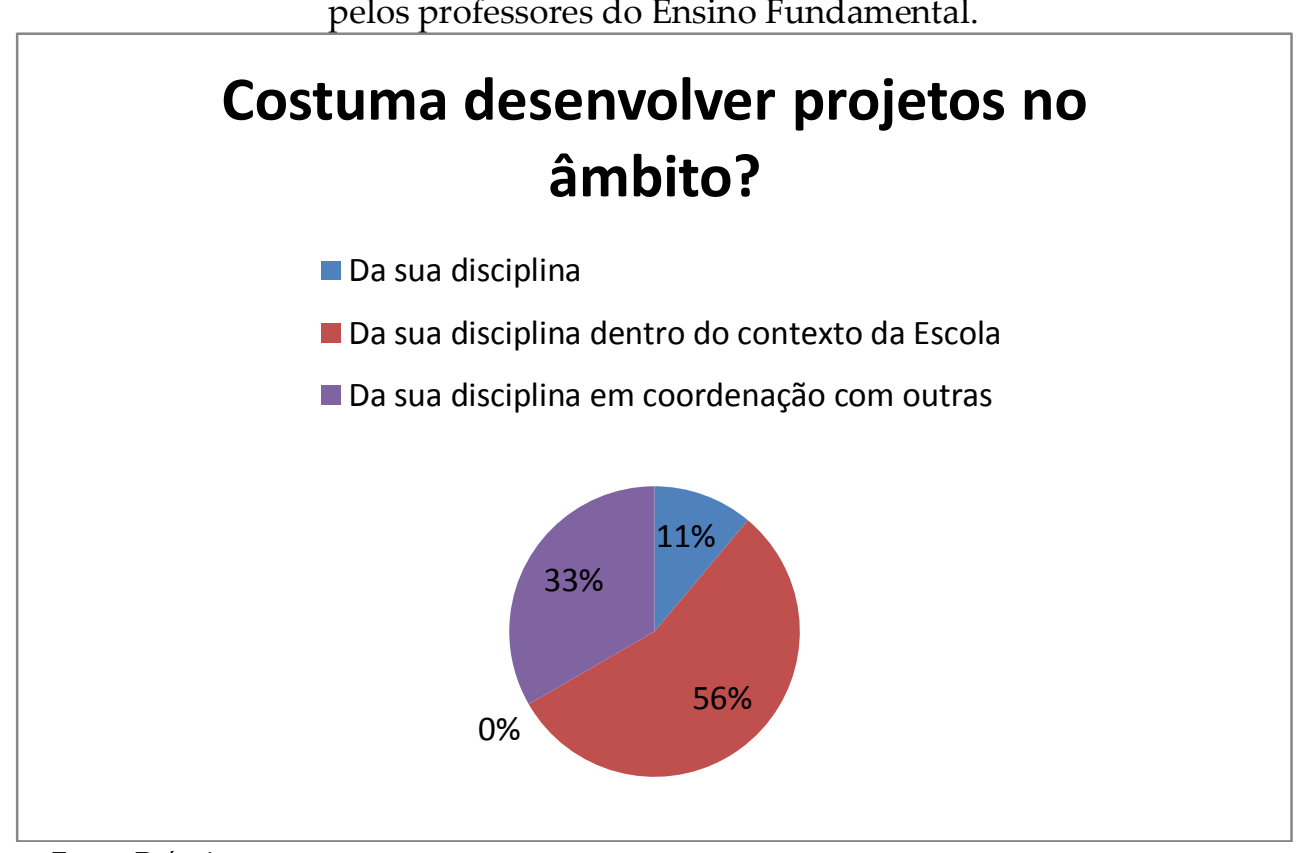

Fonte: Próprio autor.

A interdisciplinaridade, segundo Heloísa Lück (2010), é o processo que envolve a integração e o engajamento de educadores, num trabalho conjunto, de interação de disciplinas do currículo escolar entre si e com a realidade, de modo a superar a fragmentação do ensino. No entanto, superar a fragmentação das disciplinas é um desafio que necessita ser vencido. Nesse sentido, foi solicitado que os educadores indicassem alguns fatores que dificultam a prática interdisciplinar na educação básica, sendo que todos assinalaram o item que indicava a ausência de reuniões de planejamento como fator relevante.

No questionário havia representações simbólicas de multidisciplinaridade, pluridisciplinaridade e interdisciplinaridade sendo solicitado aos docentes que identificassem cada caso, conforme figura 1. Neste item ficou claro que os mesmos possuem dificuldade em diferenciar ou identificar os níveis 
apresentados sendo que apenas 04 professores relacionaram corretamente a multidisciplinaridade não ocorrendo identificação certa dos demais níveis por nenhum participante da pesquisa.

Figura 1: Representação simbólica de multidisciplinaridade, pluridisciplinaridade e interdisciplinaridade sendo aplicada no questionário trabalhado.

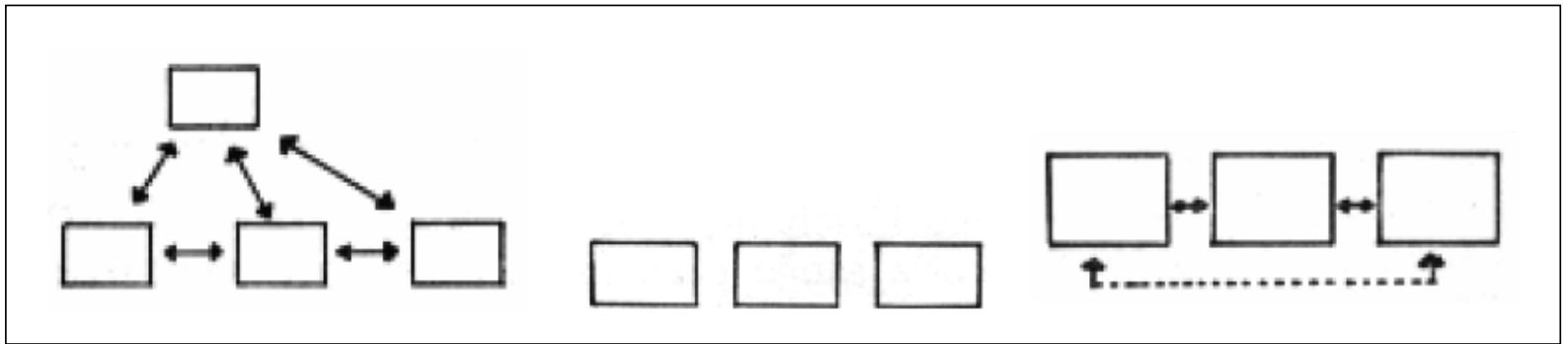

Fonte: Próprio autor.

Quando questionados quanto à forma que praticam a interdisciplinaridade, a maioria citou que o fazem através da "Ciranda do Saber" ${ }^{1 "}$, fator este que comprova o desconhecimento dos princípios, conceito e fundamentação do tema em questão.

Foi solicitado aos educadores que avaliassem a prática da interdisciplinaridade na Escola Estadual de Ensino Fundamental Ataliba Rodrigues das Chagas, sendo que 56\% deles indicaram como razoável, conforme gráfico 2.

Gráfico 2- Avaliação do trabalho interdisciplinar na escola Ataliba.

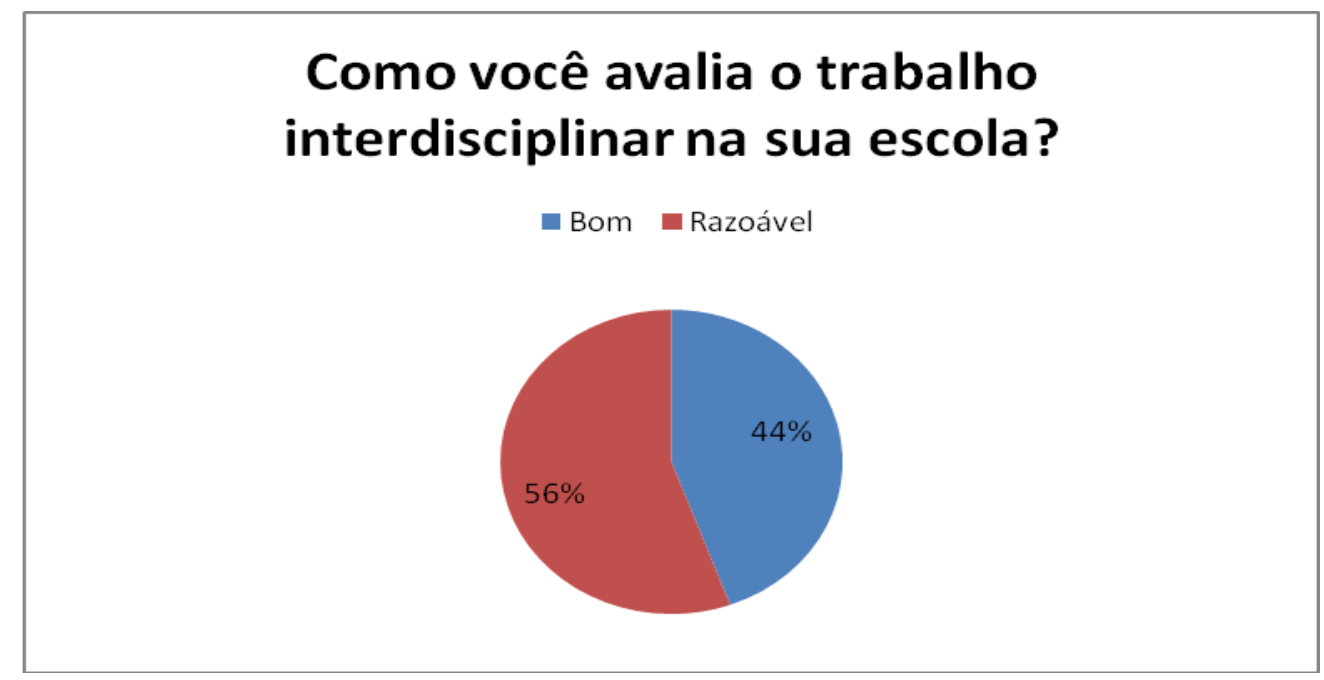

Fonte: Próprio autor.

Finalizando o questionário foi solicitado que indicassem as vantagens do trabalho interdisciplinar sendo que, todos foram unânimes em afirmar que proporciona troca de experiências e novos conhecimentos, promovendo a integração. Além de indicarem a ampliação de conhecimentos em novas disciplinas como fator importante.

A interpretação dos resultados obtidos a partir da aplicação do questionário, com a colaboração dos educadores da Escola Ataliba, foi fundamental para chegar a uma conclusão sobre a necessidade de uma posterior visita à escola de forma a ser feito um trabalho de formação a respeito do tema interdisciplinaridade, pois se percebeu através das respostas dos educadores que há pouco conhecimento a respeito desta metodologia de trabalho.

Em um segundo momento houve a intervenção sendo que esta teve início com uma dinâmica para acolhimento e motivação, intitulada "amigo secreto". 
Na sequência realizou-se abordagem expositivo-dialogada sobre o tema "Interdisciplinaridade", quando o autor desta pesquisa trouxe dados referentes ao histórico, fundamentação legal e teórica e identificação dos níveis comentados anteriormente. Neste instante, notavelmente todos realizaram uma autoavaliação quanto à questão respondida no questionário, determinando se havia acertado ou errado em sua resposta. Foi, então, apresentado modelo JANTSCH (1995), de projetos pluridisciplinares e interdisciplinares com o objetivo de esclarecer dúvidas e diferenciar as duas ações metodológicas, conforme figura 2 .

Figura 2 - Acadêmico Luiz Felipe Ribeiro, do curso de especialização, abordando o tema interdisciplinaridade na sede administrativa da Universidade Federal do Pampa.

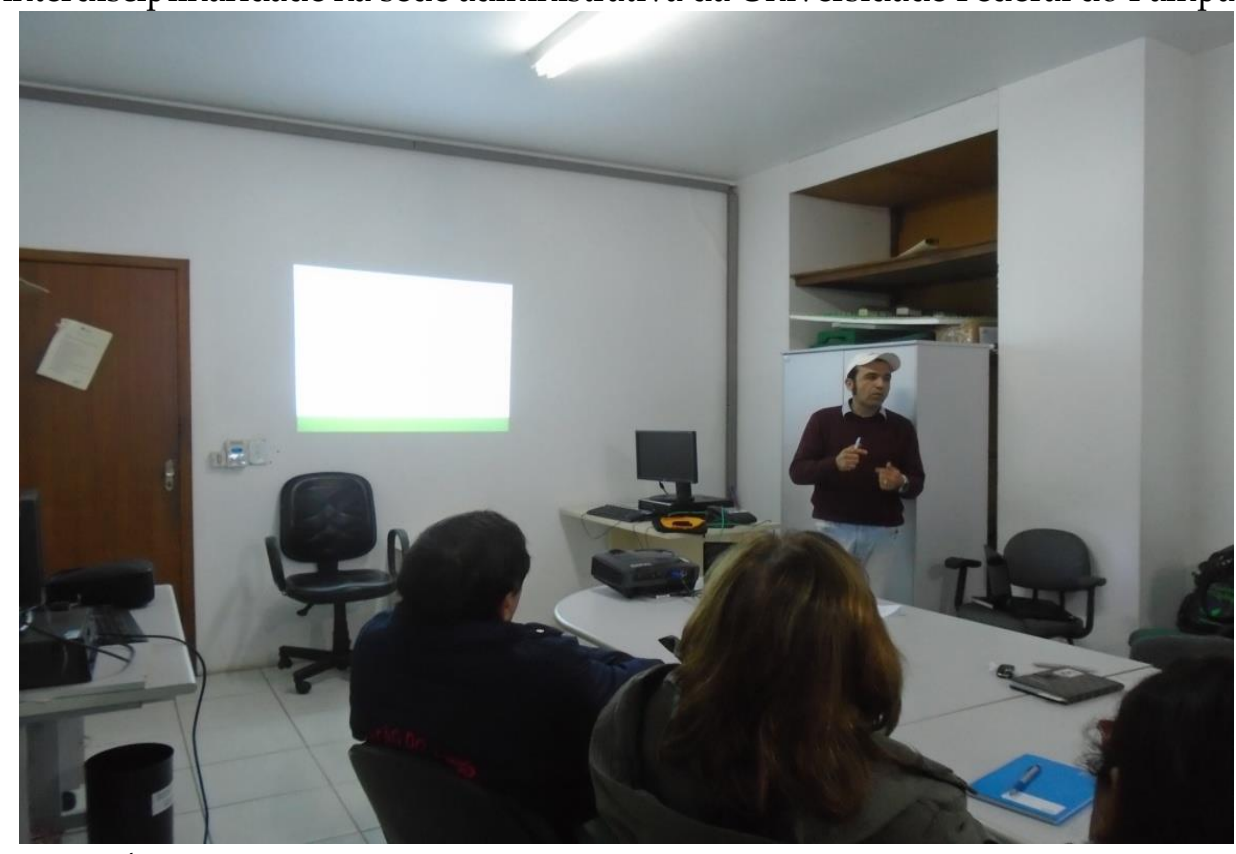

Fonte: Próprio autor

O último passo a que se propunha a atividade interventiva era a elaboração de uma proposta de projeto interdisciplinar que envolvesse um(s) tema(s) específico da Educação do Campo. Os(as) educadores quando desafiados(as) a elencar tais temas apontaram a "Educação Sexual" como assunto emergente na Escola chegando a relatar que é urgente um trabalho diferenciado com os adolescentes e jovens que frequentam a Estadual de Ensino Fundamental Ataliba Rodrigues das Chagas. Ao justificarem a escolha apontaram os seguintes fatores:

$\checkmark$ Nos momentos referentes à entrada, recreio e saída da Escola os(as) alunos(as) combinam encontros em uma casa (sede de um antigo CTG) próxima à Escola para realizarem trocas de beijos e carinhos;

$\checkmark$ As meninas utilizam roupas sensuais e, muitas vezes, inapropriadas para a temperatura/clima da época tendo em vista atingirem os meninos/rapazes com a sensualidade;

$\checkmark$ Devido ao tipo específico de moradia, construída pelas famílias que compõem o Movimento dos Trabalhadores Rurais Sem Terra (MST), onde não há divisória de quartos e pais e filhos dormem num mesmo ambiente, acredita-se que as crianças e jovens tenham acesso a momentos de certa intimidade que os despertam precocemente para a sexualidade.

No entanto, tal tema não era esperado pelo coordenador da atividade interventiva, acreditava-se que iriam emergir temas voltados para a sustentabilidade, a inclusão social, a cidadania, as lutas políticas vividas por estas comunidades afinal acreditava-se que a Escola do Campo possuía um projeto educativo próprio que atenda as necessidades daqueles que vivem e trabalham no campo.

Desta forma, inicialmente, parecia descontextualizado o tema, mas ao refletir-se sobre as ideias de Edgar Morin (2000), onde ele expõe que o papel da Escola passa pela porta do conhecimento. E esta 
deve ajudar o ser que está em formação a viver, a encarar a vida e situar-se na condição humana, diante do mundo e da vida, da sociedade, fazendo que estes conheçam a si mesmos percebeu-se então, que era esta a necessidade mais emergencial a ser atendida.

Em face dessa realidade, adotar um enfoque interdisciplinar poderia tornar-se uma alternativa para enfrentar o desafio proposto pelo tema, sendo que esta metodologia permitiria conceber a aprendizagem partindo de problematizações das quais se envolveriam diferentes campos do conhecimento e de saberes, vinculando-se a compreensão e à práxis de um problema real.

Quando o grupo foi convidado a pensar como trabalhar esse tema de forma interdisciplinar começaram a surgir obstáculos, tais como: os pais são muito críticos que não aceitam que esse tema seja trabalhado com seus filhos. Existem muitos preconceitos necessitando realizarem-se, inicialmente, reuniões com os pais para esclarecer os objetivos dos trabalhos, os professores necessitariam de curso de formação para abordar o tema, entre outros. Neste momento ficou claro que os educadores gostariam que a Universidade desenvolvesse um projeto, tirando deles a responsabilidade de planejar e executar uma ação docente.

Segundo Lino de Macedo (2013) para que um projeto interdisciplinar torne-se possível, as pessoas nele implicadas devem ter ou construir a vontade para isso. No caso da Escola Estadual de Ensino Fundamental Ataliba Rodrigues das Chagas ainda não está definido esta vontade e percebeu-se, claramente, que permanece a visão disciplinar de ação pedagógica daquele grupo docente.

\section{CONSIDERÇÕES FINAIS}

O presente artigo teve por objetivo promover um estudo em uma escola do campo para avaliar, na prática, o nível de conhecimento dos professores da Escola Estadual de Ensino Fundamental Ataliba Rodrigues das Chagas a respeito do tema "interdisciplinaridade".

Os dados apontaram alguns fatores significativos, tais como: embora a escola esteja adequada à nova proposta de funcionamento por ciclos, o currículo ainda não foi adequado conforme as necessidades da escola do campo.

Os docentes praticam o mesmo currículo e as mesmas práticas docentes aplicadas nas escolas do meio urbano que possui especificidades completamente divergentes da escola do campo. Devido ao fato de que os professores ministram aula nesta escola e em outros dois anexos (escolas filiadas) à Escola Estadual de Ensino Fundamental Ataliba Rodrigues das Chagas, durante dias alternados, torna-se difícil o encontro para estudos, reuniões de planejamento e até mesmo formação continuada.

A prática disciplinar está muito presente e consolidada no corpo docente, e, para superar fragmentação do saber decorrente da divisão das disciplinas, a interdisciplinaridade representa uma possibilidade de negociação de pontos de vista, de diálogo e de interação entre as disciplinas vigentes no currículo, a partir de reuniões de estudo, torna-se difícil aplicar tal metodologia aos discentes.

Na Escola Estadual de Ensino Fundamental Ataliba Rodrigues das Chagas a interdisciplinaridade ainda não consegue ser implementada em sala de aula, devido o pouco conhecimento e interesse a respeito do tema onde os educadores ainda estão divididos por área do conhecimento não conseguindo diferenciar um processo multidisciplinar, pluridisciplinar de um interdisciplinar.

Trabalhar na perspectiva interdisciplinar exige uma postura do educador que vai além do que está descrito nos PCNs, pois é necessário que ele assuma uma atitude interna e que faça uso de metodologias didáticas adequadas para essa perspectiva. É através do ensino interdisciplinar, dentro do aspecto histórico-crítico, que os professores possibilitarão aos seus alunos uma aprendizagem eficaz na compreensão da realidade em sua complexidade.

$\mathrm{O}$ autor desta pesquisa se propôs a auxiliar no desenvolvimento do tema proposto pelo grupo durante a atividade interventiva, no entanto, continuará com seus esforços para que a ação se dê de forma coletiva e, talvez, em determinados momentos interdisciplinar. 
A prática interdisciplinar do saber é a essência da coletividade política dos sujeitos. Em todas as esferas de sua prática, os homens atuam como sujeitos coletivos. Por isso mesmo, o saber, como expressão da prática simbolizadora dos homens, só será autenticamente humano e autenticamente saber quando se der interdisciplinarmente (SEVERINO, 2007, p. 40). A interdisciplinaridade é, portanto, elemento condicional para uma educação crítica, capaz de contribuir na formação da cidadania e na melhor distribuição do poder. Busca-se, portanto, através da interdisciplinaridade, uma educação essencialmente transformadora.

\section{REFERÊNCIAS BIBLIOGRÁFICAS}

BRASIL: Constituição da República Federativa do Brasil. Lei de Diretrizes e Bases da Educação Nacional - Lei №. $9.394 / 96$

. Ministério da Educação - MEC, Secretaria de Educação Básica. Orientações Curriculares para o Ensino Médio: Ciências da natureza, matemática e suas tecnologias. Brasília, 2002.

DESCARTES, R. Discurso sobre o método. São Paulo: Hemus, 1978.

FAZENDA, Ivani. Interdisciplinaridade: história, teoria e pesquisa. 4.ed. Campinas: Papirus, 1999.

. A Integração e interdisciplinaridade no ensino brasileiro: efetividade ou ideologia? São Paulo: Loyola, 1992.

Interdisciplinaridade: História, teoria e Pesquisa. São Paulo: Papirus, 1994.

FERREIRA, Fabiano de Jesus; BRANDÃO, Elias Canuto. Educação do Campo: um olhar histórico, uma realidade concreta Disponível em: <www.unifil.br/portal/arquivos/publicacoes/.../1/413_546_publipg.pdf.>. Acesso em: 23 julho 2015.

FERREIRO, Emília. Alfabetização em processo. São Paulo: Cortez, 1996.

GIL, A. C. Métodos e técnicas de pesquisa social. 5.ed. São Paulo: Atlas, 1999.

JAPIASSU, Hilton. Interdisciplinaridade e patologia do saber. Rio de Janeiro: Imago, 1976.

JANTSCH, Ari P.; BIANCHETTI, Lucídio. Interdisciplinaridade: para além da filosofia do sujeito. Petrópolis: Vozes, 1995.

MACEDO, Lino de. Do Impossível ao Necessário. Revista Pátio, Ano V. Março/maio 2013.

MOLINA, Mônica Castagna; FREITAS, Helana Célia de Abreu. Qual é a questão? Avanços e Desafios na Construção da Educação do Campo. Disponível em:<emaberto.inep.gov.br/inex.php/emaberto/ article/view/2652/1824>. Acesso em: 22 julho 2015.

MORIN, Edgar. Os Sete Saberes necessários à Educação do Futuro. 2.ed. São Paulo: Cortez, 2000.

Educação e complexidade: os sete saberes e outros ensaios. São Paulo: Cortez, 2002b.

PERRENOUD, P. Práticas pedagógicas, profissão docente e formação: perspectivas sociológicas. Lisboa: Dom Quixote, 1993.

PETRAGLIA, I. C. Edgar Morin: A educação e a complexidade do ser e do saber. 6.ed. Petrópolis: Vozes, 1995.

RUIZ, João Álvaro. Metodologia científica. 3.ed. São Paulo: Atlas, 1992.

SEVERINO, Antônio Joaquim. O conhecimento pedagógico e a interdisciplinaridade: o saber como intencionalização da prática. In: FAZENDA, Ivani (Org.). Didática e interdisciplinaridade. 12.ed. Campinas: Papirus, 2007.

SILVA, Delcio Barros da. A interdisciplinaridade a alcance da escola. Disponível em: http://coral.ufsm.br/lec/01_01/DelcioLC5.htm. Acesso em: 20 julho 2015. 